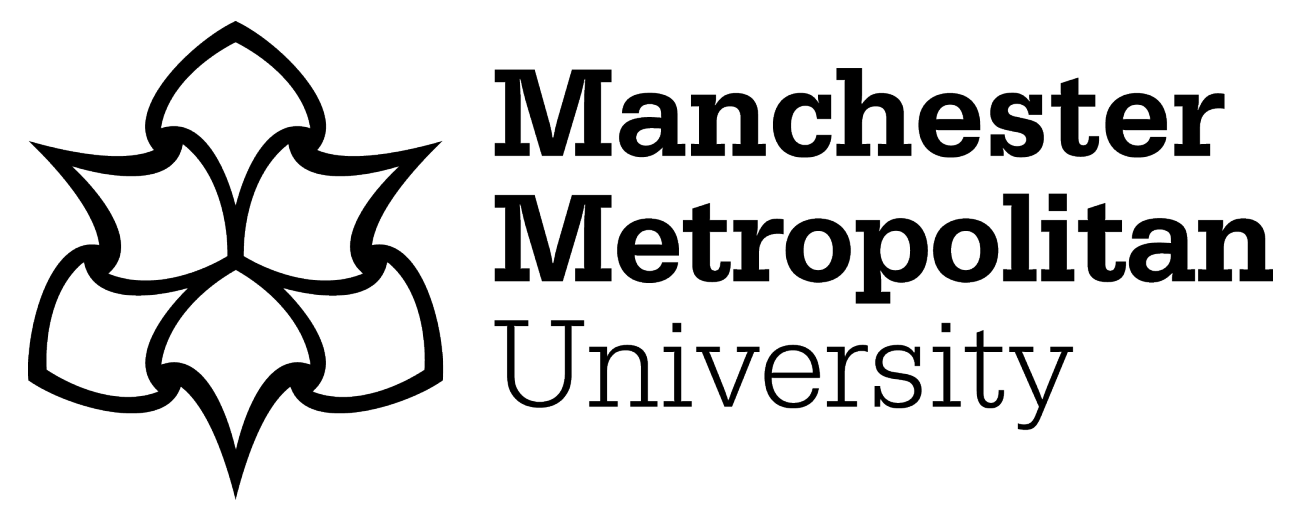

Barton, CJ, De Oliveira Silva, D, Morton, S, Collins, NJ, Rathleff, MS, Vicenzino, B, Van Middelkoop, M, Crossley, KM, Callaghan, MJ, Selfe, J ORCID logoORCID: https://orcid.org/0000-0001-9931-4998, Holden, S, Lack, S, MacRi, EM, Bazett-Jones, DM, Earl-Boehm, JE, Riel, H, Powers, CM, Davis, IS and Morrissey, D (2021) REPORT-PFP: A consensus from the International Patellofemoral Research Network to improve REPORTing of quantitative PatelloFemoral Pain studies. British Journal of Sports Medicine, 55 (20). pp. 1135-1143. ISSN 0306-3674

Downloaded from: https://e-space.mmu.ac.uk/628871/

Version: Accepted Version

Publisher: BMJ Publishing Group

DOI: https://doi.org/10.1136/bjsports-2020-103700

Please cite the published version 


\title{
REPORT-PFP: a consensus from the International Patellofemoral Research Network to improve REPORTing of quantitative PatelloFemoral Pain studies
}

\author{
Christian J Barton (D) ,'2 Danilo De Oliveira Silva (D) ,' Sarah Morton, ${ }^{3}$ \\ Natalie J Collins (D) , Michael Skovdal Rathleff, ${ }^{6}$ Bill Vicenzino (D) , \\ Marienke van Middelkoop (D) , ${ }^{8}$ Kay M Crossley (D) , ${ }^{9}$ Michael J Callaghan, ${ }^{10,11}$ \\ James Selfe, ${ }^{10}$ Sinead Holden (D) ${ }^{12,13}$ Simon Lack (D) , ${ }^{14,15}$ Erin M Macri, ${ }^{16}$ \\ David Bazett-Jones, ${ }^{17}$ Jennifer E Earl-Boehm, ${ }^{18}$ Henrik Riel (D) , ${ }^{19}$ \\ Christopher M Powers, ${ }^{20}$ Irene S Davis, ${ }^{21}$ Dylan Morrissey ${ }^{22}$
}

\begin{abstract}
- Additional supplemental material is published online only. To view, please visit the journal online (http://dx.doi. org/10.1136/bjsports-2020103700).
\end{abstract}

For numbered affiliations see end of article.

\section{Correspondence to}

Dr Christian I Barton, Sport and Exercise Medicine Research Centre, La Trobe University Bundoora Campus, Melbourne, VIC 3086, Australia; christian@completesportscare. com.au

Accepted 24 May 2021

\section{Check for updates}

(c) Author(s) (or their employer(s)) 2021. No commercial re-use. See rights and permissions. Published by BMJ.

\section{To cite: Barton CJ} De Oliveira Silva $D_{,}$

Morton $\mathrm{S}$, et al.

Br I Sports Med Epub ahead of print: [please include Day Month Year]. doi:10.1136/ bisports-2020-103700

\section{ABSTRACT}

Background Patellofemoral pain is a common and often debilitating musculoskeletal condition. Clinical translation and evidence synthesis of patellofemoral pain research is compromised by heterogenous and often inadequately reported study details. This consensus statement and associated checklist provides standards for REPORTing of quantitative PatelloFemoral Pain (REPORT-PFP) research to enhance clinical translation and evidence synthesis, and support clinician engagement with research and data collection.

Method A three-stage Delphi process was initiated at the 2015 International Patellofemoral Research Network (iPFRN) retreat. An initial e-Delphi activity $(n=24)$ generated topics and items, which were refined at the 2017 iPFRN retreat, and voted on prior to and following the 2019 iPFRN retreat ( $n=51$ current and past retreat participants). Voting criteria included 'strongly recommended' (essential), 'recommended' (encouraged) and uncertain/unsure. An item was included in the checklist if $\geq 70 \%$ respondents voted 'recommended'. Items receiving $\geq 70 \%$ votes for 'strongly recommended' were labelled as such.

Results The REPORT-PFP checklist includes 31 items (11 strongly recommended, 20 recommended), covering (i) demographics $(n=2,4)$; (ii) baseline symptoms and previous treatments $(n=3,7)$; (iii) outcome measures $(2,4)$; (iv) outcomes measure description $(n=1,2)$; (v) clinical trial methodology $(0,3)$ and (vi) reporting study results $(n=3,0)$.

Conclusion The REPORT-PFP checklist is ready to be used by researchers and clinicians. Strong stakeholder engagement from clinical academics during development means consistent application by the international patellofemoral pain research community is likely. Checklist adherence will improve research accessibility for clinicians and enhance future evidence synthesis.

\section{INTRODUCTION}

Patellofemoral pain is a common musculoskeletal condition. It affects $23 \%$ of the general population ${ }^{1}$ and accounts for approximately $17 \%$ of all knee pain presentations to general practice. ${ }^{23}$ People with patellofemoral pain presenting to sport and exercise medicine clinicians are of varying ages and activity levels, and report anterior knee pain that is aggravated by activities loading the patellofemoral joint (ie, stairs, running, squatting, etc). ${ }^{4}$

Systematic reviews, clinical practice guidelines ${ }^{5}$ and international consensus statements ${ }^{67}$ have been formulated to guide clinical practice for clinicians in how to treat people with patellofemoral pain. Yet, the credibility of recommendations and 'how to' guidance provided in these documents is compromised by heterogenous and often inadequately reported study details in the original research informing them. Our involvement in 14 key systematic review and meta-analyses published in the past 5 years to $2020^{58-20}$ has highlighted that key patient characteristics (eg, symptom duration, physical activity, body mass index (BMI), quality of life) and details of outcome measures (eg, validity, how to administer) are infrequently reported. This impedes trustworthy meta-analyses and prevents clinicians from judging the relevance of research findings to their patient population. The description of treatments provided in clinical trials often lacks sufficient detail to allow for replication in confirmatory research or use in clinical practice. ${ }^{17} 18$ For example, a 2017 review of exercise-therapy reported that no clinical trial provided complete exercise programme details to allow replication. ${ }^{17}{ }^{18}$ Frequently missing data such as group mean and variance for key outcomes in prospective ${ }^{8}$ cross-sectional $^{9-14}$ and intervention studies ${ }^{5} 101215-20$ also compromises important meta-analysis needed to better understand patellofemoral pain and guide practice.

The Enhancing the QUAlity and Transparency Of Health Research (EQUATOR) network ${ }^{21}$ curates a library of quality checklists to guide reporting of studies, that typically focuses on particular methodologies (Strengthening the Reporting of Observational Studies in Epidemiology (STROBE), Consolidated Standards of Reporting Trials (CONSORT), etc) and indicate 
The voting survey was disseminated via 'Survey Monkey' (San Mateo, USA). We sought to recruit at least 30 participants, recommended as the minimum required for stable results (ie, unlikely to change with inclusion of additional participants) based on similar Delphi studies. ${ }^{31-34}$

The following voting criteria and wording was established for voting on each item:

- Strongly recommend: these items should be included and reported in all quantitative studies related to patellofemoral pain in order to meet consensus recommendations-that is, they are essential items.

- Recommend: encouraged to be considered and reported wherever relevant to the specific research question, but may not be considered applicable (ie, N/A) for some research studies-reporting N/A is therefore also possible for these items.

- Uncertain/unsure (please explain why).

We made an a priori decision to use a $\geq 70 \%$ agreement criterion to reach consensus on an item to be strongly recommended or recommended, based on prior consensus derived recommendations. ${ }^{33}$

The pre-retreat survey finding discussion was led by CJB during the 2019 iPFRN retreat, followed by group discussions and feedback. The group also discussed the additional items proposed in pre-retreat survey responses, followed by a postretreat consensus voting survey for these items. Additionally, the group discussion led to some items that had not reached the $\geq 70 \%$ agreement criterion initially, being included for post-retreat consensus voting. Following group discussion, it was decided this survey would only include two voting options for each item-'recommend' and 'uncertain/unsure', due to the later inclusion or re-voting for these items. This final post-retreat survey (online supplemental file 3 ) provided further opportunity for feedback on items included as strongly recommended and recommended from the pre-retreat survey voting. Completion of the post-retreat survey occurred during December 2019 and January 2020. A checklist of strongly recommended and recommended reporting items, and specific suggestions for how to apply the checklist and what to report informed by author group discussion, was developed following the retreat. ${ }^{26}$

\section{RESULTS}

The consensus voting survey prior to the 2019 iPFRN retreat was completed by 51 current and past retreat participants $(49 \%$ response rate) working in 10 countries (Australia $=7$; Brazil=7; Canada $=3$; Denmark=3; India $=1 ;$ Italy $=2 ;$ Kuwait $=1$; The Netherlands $=2 ; U K=9$; USA =16). The average completion time for the 58 questions was $25 \mathrm{~min}$. There was substantial diversity in clinical experience treating patellofemoral pain patients $(\leq 4$ years $=12(24 \%) ; 5-10$ years $=9(18 \%) ; 11-15$ years $=15(29 \%) ; \geq=15(29 \%))$, time treating patients per week $(0-5$ hours $=32(63 \%) ; 5-10$ hours $=10(20 \%) ; 10-20$ hours $=3$ $(6 \%) ;>20$ hours $=6(12 \%))$ and time conducting research $(0-5$ hours $=8 \quad(16 \%) ; 5-10$ hours $=6(12 \%) ; 10-20$ hours $=9$ $(18 \%)$; > 20 hours $28(56 \%))$. Healthcare professional training of respondents included physiotherapy/physical therapy $(n=26)$, athletic trainer $(n=7)$ and medical $(n=2)$.

The consensus voting outcomes prior to the 2019 iPFRN retreat are illustrated in figure 2 (22 items related to demographics, baseline symptoms and previous treatments), figure 3 (nine items related to outcome measures) and figure 4 (10 items related to trial methodology and study results). During this voting round, no consistent recommendations were provided in

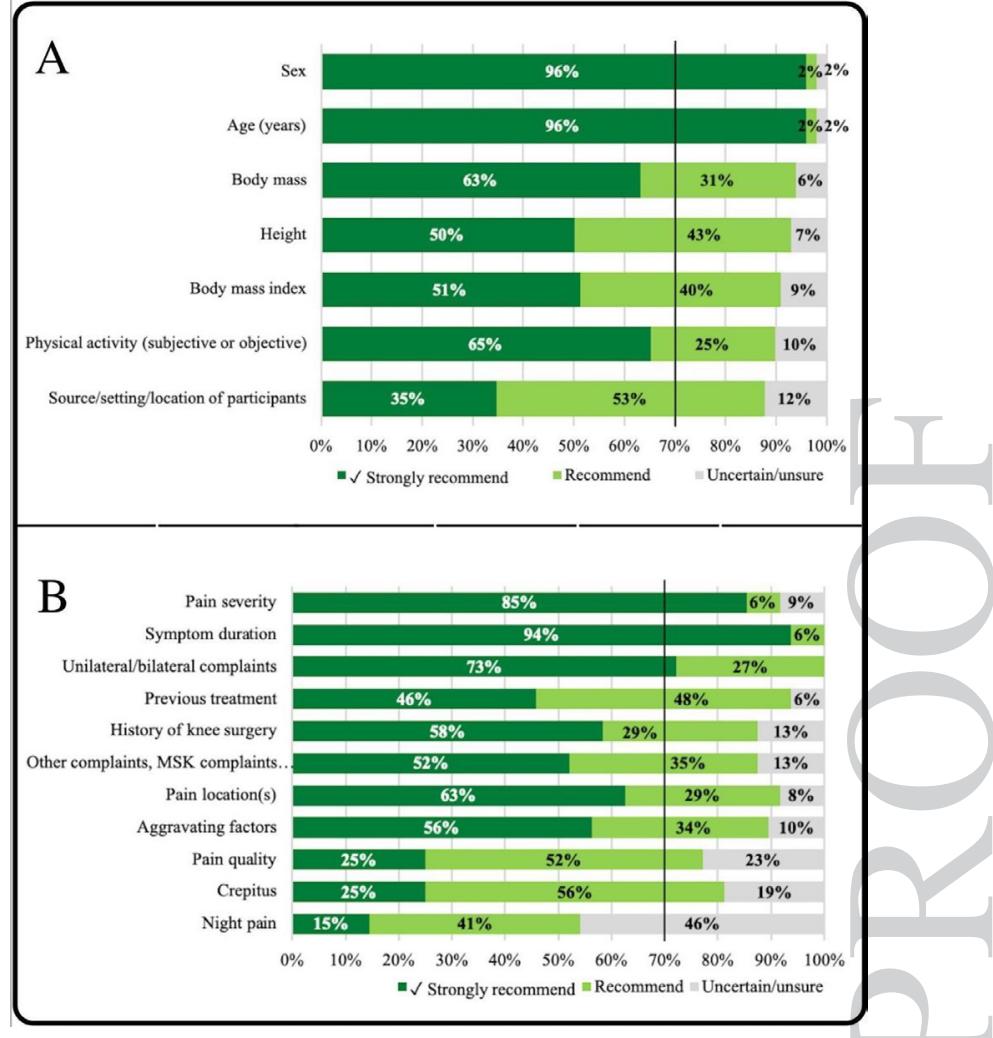

Figure 2 Consensus voting results for reporting demographics (A) and baseline symptoms and previous treatments (B). Vertical bar indicates $70 \%$ threshold for strongly recommended (dark green crosses line) or recommended (light green crosses line). MSK, musculoskeletal.

open ended responses to what should define short-term (ranged 2 weeks to 6 months), medium-term (ranged 2 weeks to 5 years) and long-term (ranged 4 weeks to $>5$ years).

The consensus voting survey after the 2019 iPFRN retreat was completed by 48 participants (46\% response rate) working in nine countries (Australia $=6$; Brazil $=6$ Canada $=2$; Denmark $=4$; Italy $=1 ; \quad$ The Netherlands $=3 ; \quad$ Switzerland $=1 ; \quad U K=7$; USA =18). Additional voting outcomes after the 2019 iPFRN retreat are illustrated in figure 5 (six items related to demographics and outcome measures). The final question 'Do you have any final comments or suggestions?' led to 11 responses. All indicated acceptance of the checklist, and no concerns or suggested changes to the items to be included as strongly recommended or recommended were raised.

\section{Strongly recommended items}

Eleven items voted on were strongly recommended for reporting ( $\geq 70 \%$ voted strongly recommended), including demographic items age and sex (figure 2A); baseline symptom items pain severity, symptom duration and unilateral/bilateral symptoms (figure 2B); outcome measure items condition-specific patientreported outcomes and pain severity (figure 3A); outcome measure description item describe assessment in adequate detail to allow replication (figure $3 \mathrm{~B}$ ); and reporting study results items reporting mean (SD), median (IQR) and 95\% CIs for between group differences (figure 4B). Suggestions on what to report for each strongly recommended (ie, essential) item provided by the author panel are provided in online supplemental file 4, and are freely available in online (www.ipfrn.org). 


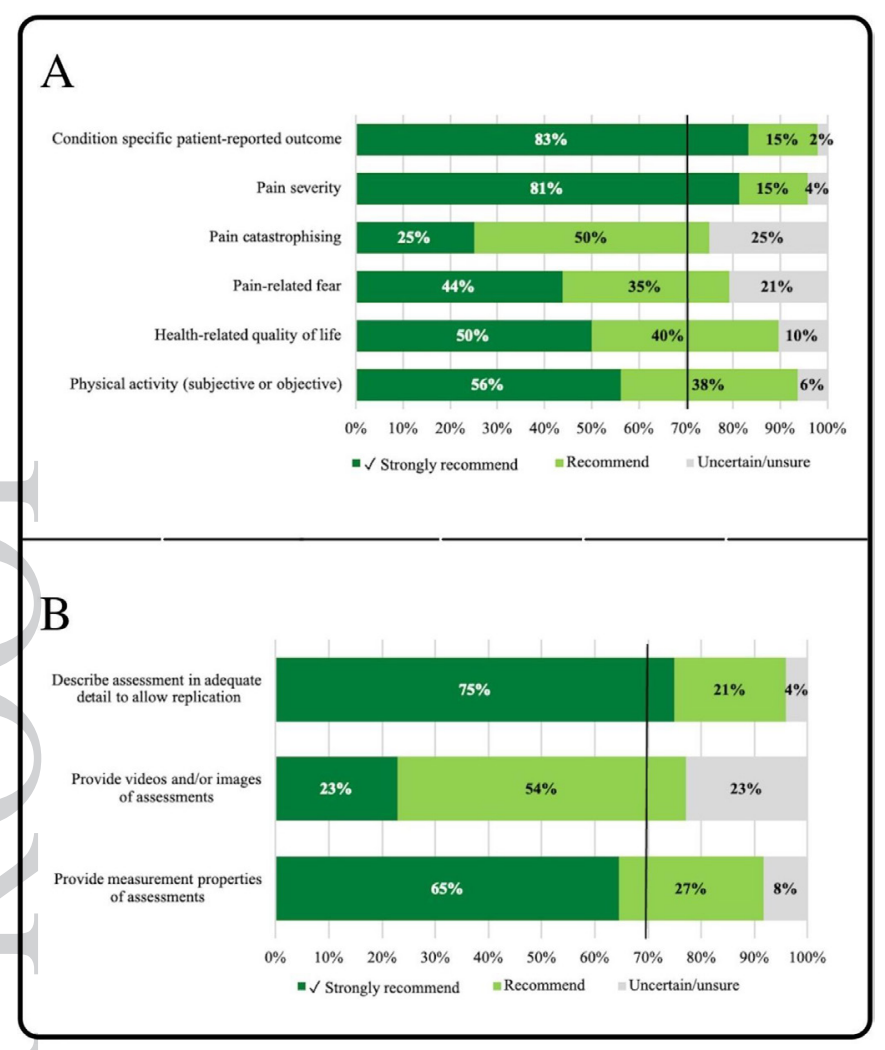

Figure 3 Consensus voting results for outcome measures $(A)$ and outcome measure description (B). Vertical bar indicates 70\% threshold for strongly recommended (dark green crosses line) or recommended (light green crosses line).

\section{Recommended items}

Twenty-eight items voted on were recommended ( $\geq 70 \%$ voted recommended or strongly recommended), including body mass, height, BMI, physical activity and source/setting/ location of participants (figure 2A); history of knee surgery, pain location, pain quality, crepitus, aggravating factors, other complaints/ musculoskeletal complaints/comorbidities (figure 2B) and ethnicity (figure 5); pain catastrophising, pain-related fear, healthrelated quality of life, physical activity (figure 3A), and global rating of change (GROC) and self-efficacy (figure 5); providing measurement properties of assessments and providing videos and/or images of assessments (figure 3B); following reporting guidelines from Complete Exercise Reporting Template (CERT), Template of Intervention Description and Replication (TIDiER), Toigo and Boutellier and EQUATOR, providing videos and/or images of treatments (figure 4A); and including 6, 13, 26 and 52 weeks as preferred follow-up timeframes (figure 4B). Suggestions on what to report for each recommended (ie, encouraged but not essential) item from the author panel are provided in online supplemental file 4 , and are freely available in online ( www.ipfrn.org).

\section{Not recommended/unsure}

Four items did not reach consensus thresholds for recommended, including baseline symptom item night pain (figure 2B); and demographic items socioeconomic status, work status and geographical location (figure 5).

\section{Final checklist}

All 11 strongly recommended (essential) items were included in the final checklist. The number of recommended (encouraged) items was reduced from 28 to 20 in the final checklist, facilitated via mergers and omissions. Specifically, (i) the three anthropometric measures (height, body mass, BMI) were combined; (ii) the three psychological outcome measures (self-efficacy, painrelated fear, pain catastrophising) were combined; (iii) the three existing checklists for interventions (TIDiER, CERT, Toigo and Boutellier) were combined and (iv) two study results items were removed (aim for longer follow-up; use 6 weeks, 3, 6 and 12 months as follow-up time points). The final REPORT-PFP checklist is provided in table 1 , and freely available in online ( www.ipfrn.org).

\section{DISCUSSION}

The 31-item REPORT-PFP checklist will enhance clinical practice by improving research reporting and translation. It will also facilitate evidence synthesis, and guide clinicians on how they can contribute to research and data collection in their practice. We used thorough and engaging iterative methods to develop the checklist. ${ }^{26}$ This included guidance from an international expert panel, face-to-face and online consultation with large numbers of international patellofemoral pain researchers and clinicians, and multiple consensus voting rounds. Multiple opportunities for feedback were provided, and suggestions were incorporated before finalising the checklist and guidance. ${ }^{26}$ Our comprehensive approach resulted in most items being recommended through consensus voting. We encourage peer reviewers and editors to consider submission of the REPORT-PFP checklist with all quantitative patellofemoral pain studies, and emphasise

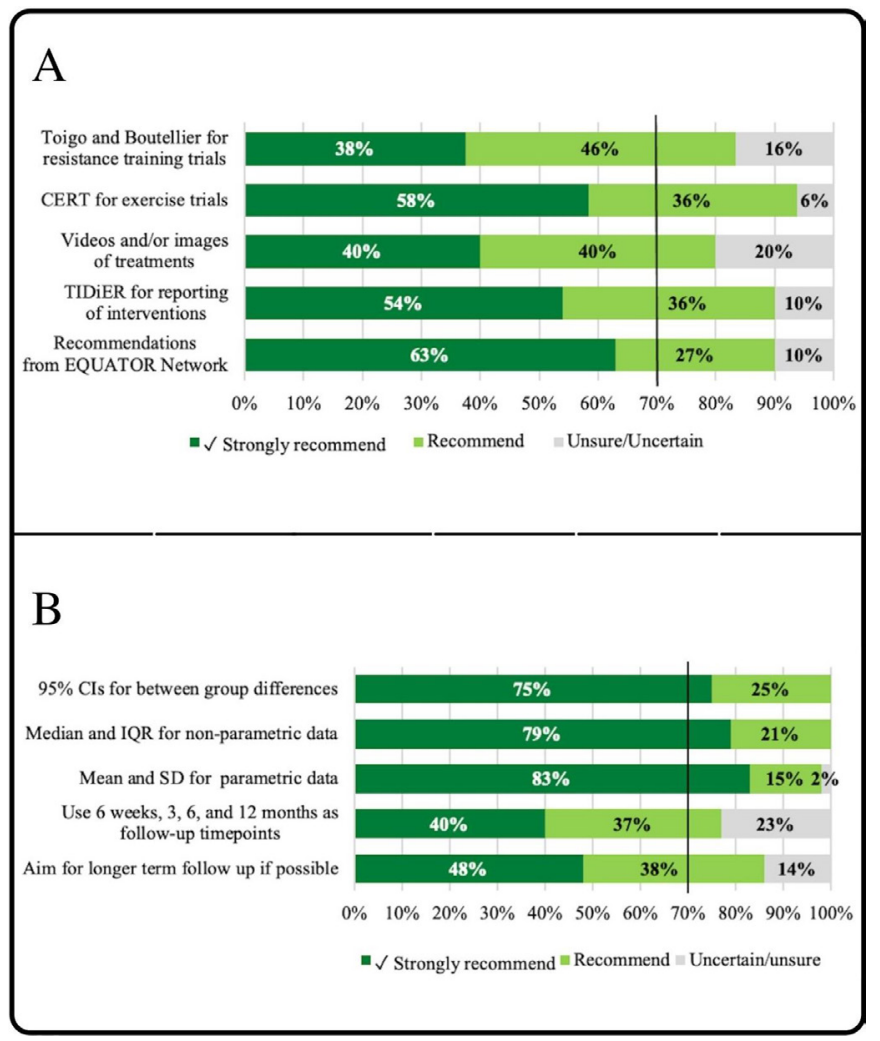

Figure 4 Consensus voting results for reporting trial methodology (A) and reporting study results (B). Vertical bar indicates $70 \%$ threshold for strongly recommended (dark green crosses line) or recommended (light green crosses line). CERT, Complete Exercise Reporting Template; EQUATOR, Enhancing the QUAlity and Transparency OfHealth Research; TIDiER, Template of Intervention Description and Replication. 


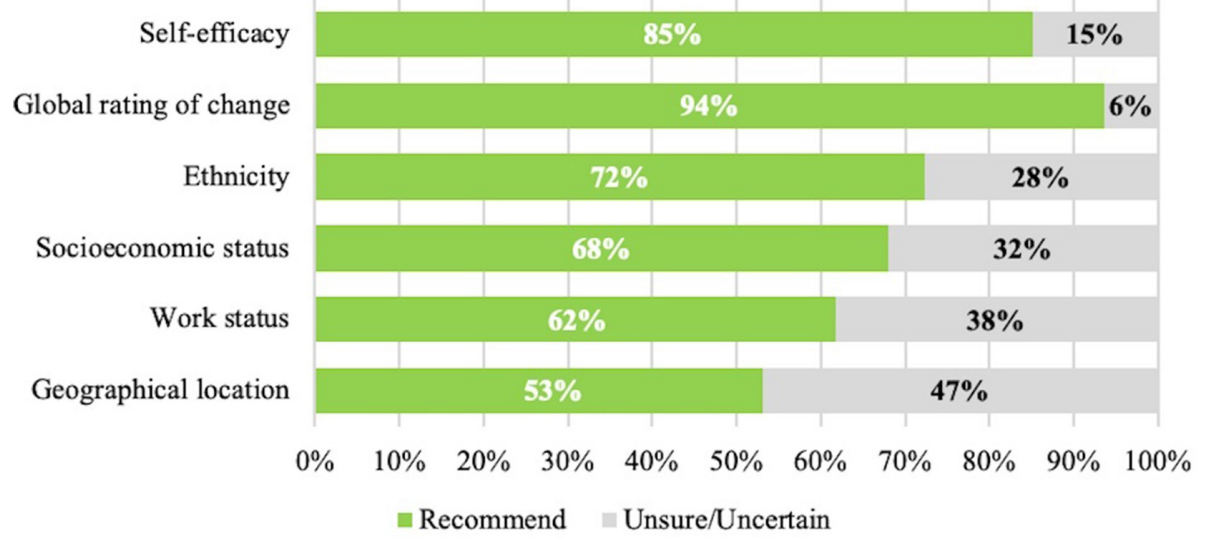

Figure 5 Consensus voting results for items discussed at the International Patellofemoral ResearchNetwork 2019 retreat and voted on after the retreat. Vertical bar indicates $70 \%$ threshold for recommended (light green crosses line).

adherence to the 11 'strongly recommended' items. The full checklist and associated recommendations of what to report (online supplemental appendix 4) will be freely available on the iPFRN website (https://ipfrn.org/report-pfp-checklist/) to guide researchers and clinicians.

\section{Strongly recommended items}

Two demographic and three baseline symptom items are strongly recommended (table 1), with adherence needed to improve evidence synthesis, and for clinicians to understand the applicability of patellofemoral pain research findings to their patients. Participants' sex is important, considering differences in muscle capacity and biomechanics between men and women with patellofemoral pain. ${ }^{35-39}$ Age is associated with greater muscle capacity impairments ${ }^{39} 40$ and development of patellofemoral osteoarthritis. $^{41}{ }^{42}$ Pain severity and symptom duration can impact prognosis in people with patellofemoral pain. ${ }^{14}$ Presence of unilateral or bilateral symptoms may reflect the magnitude of widespread pain and severity ${ }^{10}$ and/or reflect symmetrical mechanical features believed to relate to patellofemoral pain, ${ }^{43}$ and could impact symptoms and prognosis.

Reporting pain severity and a condition-specific patientreported outcome were strongly recommended, and will enable direct relationship of research findings to clinical presentations. We did not seek consensus on specific outcome measures, but further work with patients to address this will be carried out around the 2022 iPFRN retreat. In the interim, guidance notes provided in the REPORT-PFP checklist include suggestions of two condition-specific outcome measures-the Anterior Knee Pain Scale (AKPS) $)^{44}$ and/or Knee injury and Osteoarthritis Outcome Score Patellofemoral subscale (KOOS-PF). ${ }^{45}$ The $\mathrm{AKPS}^{44}$ is the most widely used condition-specific outcome for patellofemoral pain, and is valid, responsive, and has excellent reliability in this population (intraclass correlation coefficient $=0.81) .{ }^{46}$ KOOS-PF, ${ }^{45}$ published in 2018 , was developed with input from 50 patients with patellofemoral pain and/or osteoarthritis and 14 healthcare professionals. Initial evaluation following the COSMIN checklist indicates adequate measurement properties, including internal consistency, test-retest reliability, validity and responsiveness. ${ }^{45}$ Regardless of outcome measure choice, describing them in adequate detail to allow replication is strongly recommended, and will assist replication studies and ensure clinicians can confidently apply evidencebased assessments in their clinical practice, reducing research waste. ${ }^{47}$
Reporting mean and SD for parametric data and median and IQR for non-parametric data, and 95\% CIs for between-group differences is strongly recommended. These items were originally considered in the context of randomised controlled trial designs and between group differences. Following final consideration, we also recommend that precision of estimate should be provided for all inferential statistics, as is recommended in reporting guides for observational studies such as STROBE. ${ }^{48}$ Adherence to these strong recommendations reflect EQUATOR Network tools, ${ }^{21}$ and will address historic barriers to data synthesis and meta-analysis experienced by patellofemoral pain researchers seeking to guide clinical practice.

\section{Recommended items}

Reporting the 20 'recommended' items from the checklist will help clinicians interpret if the study's findings are applicable to the patient in front of them. Adherence will also reduce challenges frequently faced by researchers completing evidence synthesis due to heterogenous and often inadequately reported study details. Additionally, recommended items can also be used to guide planning of future research related to patellofemoral pain, including potential contribution to data collection by practicing clinicians. Suggestions for implementation, including specific instruments, are provided in online supplemental file 4). Recommended demographic items including body mass, height and BMI have been inconsistently reported in past research, ${ }^{811}$ and physical activity ${ }^{49}$ and ethnicity are seldomly reported. Yet each may plausibly influence prognosis and treatment outcomes, ${ }^{50-52}$ making them important considerations when interpreting research findings. Recommended baseline symptom items including knee crepitus, pain quality, pain location and aggravating factors, will help researchers and clinicians understand the important characteristics of the population being investigated. For example, crepitus is associated with fear of damage, ${ }^{53}$ patellofemoral osteoarthritis on imaging ${ }^{54}$ and risk of symptomatic knee osteoarthritis development, ${ }^{55}$ all of which may influence prognosis and adherence to treatments such as exercise-therapy. Previous treatment, knee surgery history and other musculoskeletal complaints, and comorbidities may also influence prognosis, ${ }^{56}$ making them important to know.

Inclusion of GROC, ${ }^{57}$ psychological outcome measures (painrelated fear, pain catastrophising, self-efficacy), and healthrelated quality of life alongside self-reported pain and disability outcomes (eg, $\mathrm{AKPS}^{44}$ ) may provide important insight into treatment outcomes and prognosis. ${ }^{913}{ }^{58-61}$ Building on the strong 
Table 1 Checklist of strongly recommended and recommended items for quantitative patellofemoral pain studies

\begin{tabular}{|c|c|c|}
\hline \multicolumn{2}{|c|}{$\begin{array}{l}\text { Section } 1 \text {-items strongly recommended } \\
\text { (essential) }\end{array}$} & $\begin{array}{l}\text { Reported on page \# } \\
\text { or N/A }\end{array}$ \\
\hline \multicolumn{3}{|c|}{ Demographic items } \\
\hline 1 & Sex or gender of the participants & \\
\hline 2 & Age of the participants & \\
\hline \multicolumn{3}{|c|}{ Baseline symptoms and previous treatment items } \\
\hline 3 & Symptom duration & \\
\hline 4 & Pain severity & \\
\hline 5 & Unilateral/bilateral complaints & \\
\hline \multicolumn{3}{|c|}{ Outcome measure items } \\
\hline 6 & Condition-specific patient-reported outcome & \\
\hline 7 & Pain severity & \\
\hline \multicolumn{3}{|c|}{ Outcome measure description } \\
\hline 8 & $\begin{array}{l}\text { Describe assessment in adequate detail to allow } \\
\text { replication }\end{array}$ & \\
\hline \multicolumn{3}{|c|}{ Reporting study results items } \\
\hline 9 & Mean and SD for parametric data & \\
\hline 10 & Median and IQR for non-parametric data & \\
\hline 11 & $\begin{array}{l}\text { Precision of estimate for all inferential statistics } \\
\text { (eg, } 95 \% \mathrm{Cl} \text { for between group differences) }\end{array}$ & \\
\hline
\end{tabular}

Section 2-items recommended $\quad$ Reported on page \#

(encouraged) or N/A

\section{Demographic items}

12 Anthropometrics (including body mass and height, or body mass index)

13 Physical activity

14 Source/setting/location of participants

15 Ethnicity of the participants

Baseline symptoms and previous treatment items

16 Previous treatment

17 Pain location(s)

$18 \quad$ Aggravating factors

19 History of knee surgery

20 Other complaints, musculoskeletal complaints and comorbidities

$21 \quad$ Crepitus

22 Pain quality

Outcome measure items

23 Physical activity

24 Global rating of change

25 Health-related quality of life

26 Psychological factors (including self-efficacy, painrelated fear and pain catastrophising)

Outcome measure description

27 Provide measurement properties of assessments

28 Provide videos and/or images of assessments

Study methodology items, including reporting interventions

29 Follow recommendations from EQUATOR Network ${ }^{21}$

30 Use existing checklists for interventions, including TIDiER ${ }^{66}$; CERT ${ }^{67} 68$ for exercise interventions; and

Toigo and Boutellier ${ }^{1769}$ for resistance training interventions

$31 \quad$ Provide videos and/or images of treatments

CERT, Complete Exercise Reporting Template; EQUATOR, Enhancing the QUAlity and Transparency Of health Research; N/A, not applicable; TIDiER, Template of Intervention Description and Replication.

recommendation to describe outcome measures in adequate detail to allow replication, providing, or linking to, videos and/ or images of any assessment or outcome measures is also recommended where possible. This can facilitate important 'how to' guidance for clinicians to implement new assessments into practice, ${ }^{62}$ and improve the ease of completing replication studies for other research groups. ${ }^{47}$ Additionally, providing measurement properties including reliability and validity of those performing assessments will ensure the trustworthiness of data is clear to researchers and clinicians. ${ }^{63}$ Our consensus process could not provide consistent definitions for short-term, medium-term and long-term timeframes. However, the consistent use of 6, 13, 26 and 52 weeks follow-up where possible for clinical trials was recommended through consensus voting.

Consensus voting supported EQUATOR Network ${ }^{21}$ recommendations for relevant study designs (eg, CONSORT, ${ }^{64}$ $\mathrm{STROBE}^{65}$ ), including the TIDiER checklist ${ }^{66}$ to report interventions with the addition of CERT ${ }^{6768}$ for exercise interventions. Adherence to these recommendations will help to address previous challenges with evidence synthesis and allow replication in future studies and clinical practice. For example, there is clear evidence that inadequate reporting of exercise-therapy programmes for patellofemoral pain has prevented recommendations about what type of exercise-therapy, if any, might be best. ${ }^{17}$ Beyond the EQUATOR Network, ${ }^{21}$ the REPORT-PFP provides important additional recommendations related to intervention reporting. Studies evaluating resistance training interventions are recommended to include detailed information based on the Toigo and Boutellier criteria, ${ }^{1769}$ and provide videos and/or images of all interventions where possible to aid with replication in research and clinical practice. ${ }^{4762}$

\section{Clinical implications}

Systematic reviews, consensus statements and clinical practice guidelines are typically highly cited, meaning they are often considered of high quality by researchers and funders, ${ }^{70}$ and are sought by quality journals. Yet, the heterogeneous and inadequate reporting of study details in patellofemoral pain research has meant the credibility of these evidence syntheses is frequently hampered. Additionally, no guideline has been able to provide clear guidance on 'how to' apply assessment and treatment recommendations for patellofemoral pain in clinical practice. ${ }^{71}$ Ultimately, this reduces the trust clinicians place in using research to inform care they provide, stifling the translation of evidence and guidelines to practice, as is evident in the management of patellofemoral pain. ${ }^{72}$ Our work to develop and disseminate the REPORT-PFP checklist was urgently needed to improve the trustworthiness of evidence syntheses, and help clinicians optimise evidence-based practice. If translatable research findings such as effective intervention are more readily applied by clinicians, this will improve research impact through improved health outcomes. ${ }^{74}$ Our checklist and guidance notes (online supplemental appendix 4) will guide clinicians on how to embed data collection in their practice, and thus can facilitate development of a vital 'real world' evidence-base for one of the most commonly encountered musculoskeletal conditions. ${ }^{1}$

\section{Limitations}

Although we conducted extensive face-to-face and online consultation with the international patellofemoral research community, 20 of our 31 items were categorised as 'recommended', rather than 'strongly recommended'. Our consensus voting to develop the REPORT-PFP checklist did not include patient voices and further work is planned to address this. This will focus on refining items included (ie, how/what to specifically report-eg, which patient reported outcomes). We expect this work will lead to many 'recommended' items becoming 'strongly recommended' 
in the future. Health professional training of our experts in the final round of consensus voting (2019) was predominantly physiotherapy/physical therapy (52\%), with limited representation of researchers with a medical training $(8 \%)$. The consensus participants are representative of the main research and clinical community treating patellofemoral pain. However, seeking additional feedback and critique of this checklist from general practitioners, rheumatologists, sports physicians and surgeons, who also commonly manage and research people with patellofemoral pain, may help to optimise acceptance and adoption.

We have not provided specific guidance for reporting biomechanical and imaging research in people with patellofemoral pain, with further work planned to extend the checklist to cover these specific fields of research. A concurrent iPFRN consensus related to pain and psychological features in the field of patellofemoral pain was developed during the 2019 iPFRN retreat, ${ }^{75}$ providing guidance to researchers working in these fields. Evaluating uptake and effectiveness of the REPORT-PFP checklist, and iterative refinement will be priorities for this group. User feedback will be facilitated via an embedded survey on the iPFRN website (https://ipfrn.org/report-pfp-checklist/), allowing researchers and clinicians to evaluate usability and applicability, and providing an opportunity for suggestions on refinement. We expect the REPORT-PFP checklist to evolve based on this feedback, emerging evidence, understanding related to patellofemoral pain, and patient input. Any updates will be provided via the iPFRN website.

\section{CONCLUSION}

Strong recommendations about what essential items should be reported, along with a larger list of recommended items that should be considered in future patellofemoral pain research are provided. Strong stakeholder engagement during development of the REPORT-PFP checklist means consistent application by the international patellofemoral pain research community is likely. Adherence to the checklist, which provides standards for REPORT-PFP should improve clinical translation, clarity and trustworthiness of evidence syntheses, and guide sports medicine clinicians on how to collect data in their own practice.

\section{Author affiliations}

${ }^{1}$ Sport and Exercise Medicine Research Centre, La Trobe University - Bundoora Campus, Melbourne, Victoria, Australia

${ }^{2}$ Complete Sports Care, Hawthorn, Victoria, Australia

${ }^{3}$ La Trobe Sport and Medicine Research Centre (LASEM), La Trobe University, Bundoora / Melbourne, Victoria, Australia

${ }^{4}$ Centre for Sports and Exercise Medicine, London, UK

${ }^{5}$ School of Health and Rehabilitation Sciences, The University of Queensland, Brisbane, Queensland, Australia

${ }^{6}$ Department of Clinical Medicine, Aalborg University, Aalborg University Hospital, Aalborg, Denmark

${ }^{7}$ Physiotherapy, The University of Queensland, Saint Lucia, Queensland, Australia

${ }^{8}$ General Practice, Erasmus Medical Center, Rotterdam, The Netherlands

9 La Trobe University - Bundoora Campus, Bundoora, Victoria, Australia

${ }^{10}$ Department of Health Professions, Manchester Metropolitan University,

Manchester, UK

${ }^{11}$ Medical, Manchester United Football Club Ltd, Manchester, UK

${ }_{12}^{12}$ Department of Clinical Medicine, Aalborg University, Aalborg, Denmark

${ }^{13}$ SMI, Department of Health Science and Technology, Aalborg University, Aalborg, Denmark

${ }^{14}$ Sports and Exercise Medicine, Queen Mary University of London, London, UK

${ }^{15}$ Pure Sports Medicine, London, UK

${ }^{16}$ Erasmus MC, Rotterdam, The Netherlands

${ }^{17}$ University of Toledo - Health Science Campus, Toledo, Ohio, USA

${ }^{18}$ Department of Kinesiology, University of Wisconsin-Milwaukee, Milwaukee, Wisconsin, USA

${ }^{19}$ Center for General Practice at Aalborg University, Aalborg, Denmark

${ }^{20}$ University of Southern California, Los Angeles, California, USA
${ }^{21}$ Spaulding National Running Center, Department of Physical Medicine and Rehabilitation, Harvard Medical School, Cambridge, Massachusetts, USA

${ }^{22}$ School of Medicine and Dentistry, Queen Mary, University of London, London, UK

Twitter Christian J Barton@DrChrisBarton, Danilo De Oliveira Silva @DrDanilo Silva, Natalie J Collins @NatJCollins, Bill Vicenzino @Bill_Vicenzino, Marienke van Middelkoop @mvanmiddelkoop, Sinead Holden @Sinead_Holden, Simon Lack @simonthephysio, Henrik Riel @Henrik_Riel and Dylan Morrissey @DrDylanM

Acknowledgements The authors wish to acknowledge all attendees at the 2015, 2017 and 2019 iPFRN retreats for their contributions to discussions which informed this consensus and the REPORT-PFP checklist.

Contributors Initial research design was carried out by DM, CJB and SM following the 2015 retreat led by MJC and JS. Initial survey content was guided by DM, CJB, SM, MJC, MvM, KMC, MSR and BV. SM, CJB and DM analysed stage 1 findings to inform subsequent stages. NJC and BV facilitated the 2017 retreat. Stage 2 small group discussions were led by CJB, DDOS, NJC, MSR, BV, MVM, KMC, MJC, JS, SH, SL, EMM, CMP and ISD. CJB, MVM, KMC, MSR, BV, NJC and DM developed the final consensus voting surveys. DB-J and JEE-B facilitated the 2019 retreat and voting on potential checklist items. CJB coordinated final consensus discussions. CJB and DDOS led synthesis of results following consensus voting surveys. All authors contributed to read and approved the final manuscript.

Funding The authors have not declared a specific grant for this research from any funding agency in the public, commercial or not-for-profit sectors.

Competing interests None declared.

\section{Patient consent for publication Not required.}

Ethics approval The design and conduct of the study was approved by the Queen Mary University of London research ethics committee (QMREC2014/24/55). Experienced clinicians and academics, research active in the patellofemoral pain field participated in all stages. Informed consent was provided via a tick box for each voting activity.

Provenance and peer review Not commissioned; externally peer reviewed.

Supplemental material This content has been supplied by the author(s). It has not been vetted by BMJ Publishing Group Limited (BMJ) and may not have been peer-reviewed. Any opinions or recommendations discussed are solely those of the author(s) and are not endorsed by BMJ. BMJ disclaims all liability and responsibility arising from any reliance placed on the content. Where the content includes any translated material, BMJ does not warrant the accuracy and reliability of the translations (including but not limited to local regulations, clinical guidelines, terminology, drug names and drug dosages), and is not responsible for any error and/or omissions arising from translation and adaptation or otherwise.

\section{ORCID iDs}

Christian J Barton http://orcid.org/0000-0002-2489-5350

Danilo De Oliveira Silva http://orcid.org/0000-0003-0753-2432

Natalie J Collins http://orcid.org/0000-0001-9950-0192

Bill Vicenzino http://orcid.org/0000-0003-0253-5933

Marienke van Middelkoop http://orcid.org/0000-0001-6926-0618

Kay M Crossley http://orcid.org/0000-0001-5892-129X

Sinead Holden http://orcid.org/0000-0002-7314-2152

Simon Lack http://orcid.org/0000-0003-1732-9606

Henrik Riel http://orcid.org/0000-0003-4575-6293

\section{REFERENCES}

1 Smith BE, Selfe J, Thacker D, et al. Incidence and prevalence of patellofemoral pain: a systematic review and meta-analysis. PLoS One 2018;13:e0190892.

2 van Middelkoop M, van Linschoten R, Berger MY, et al. Knee complaints seen in general practice: active sport participants versus non-sport participants. $B M C$ Musculoskelet Disord 2008:9:36.

3 Wood L, Muller S, Peat G. The epidemiology of patellofemoral disorders in adulthood: a review of routine general practice morbidity recording. Prim Health Care Res Dev 2011;12:157-64

4 Crossley KM, Callaghan MJ, van Linschoten R. Practice pointer Patellofemoral pain. BMJ 2015;351. doi:10.1136/bmj.h3939

5 Willy RW, Hoglund LT, Barton CJ, et al. Patellofemoral pain. J Orthop Sports Phys Ther 2019;49:CPG1-95. doi:10.2519/jospt.2019.0302

6 Collins NJ, Barton CJ, van Middelkoop M, et al. 2018 consensus statement on exercise therapy and physical interventions (orthoses, taping and manual therapy) to treat patellofemoral pain: recommendations from the 5th International Patellofemoral pain research retreat, gold Coast, Australia, 2017. Br J Sports Med 2018;52:1170-8. doi:10.1136/bjsports-2018-099397

7 Crossley KM, van Middelkoop M, Callaghan MJ, et al. 2016 Patellofemoral pain consensus statement from the 4th International Patellofemoral pain research retreat, 
Manchester. Part 2: recommended physical interventions (exercise, taping, bracing, foot orthoses and combined interventions). Br J Sports Med 2016;50:844-52.

8 Neal BS, Lack SD, Lankhorst NE, et al. Risk factors for patellofemoral pain: a systematic review and meta-analysis. Br J Sports Med 2019;53:270-81.

9 Coburn SL, Barton CJ, Filbay SR, et al. Quality of life in individuals with patellofemora pain: a systematic review including meta-analysis. Phys Ther Sport 2018;33:96-108.

10 De Oliveira Silva D, Rathleff MS, Petersen K, et al. Manifestations of pain sensitization across different painful knee disorders: a systematic review including meta-analysis and metaregression. Pain Med 2019;20:335-58.

11 Hart HF, Barton CJ, Khan KM, et al. Is body mass index associated with patellofemoral pain and patellofemoral osteoarthritis? A systematic review and meta-regression and analysis. Br J Sports Med 2017;51:781-90.

12 Neal BS, Barton CJ, Gallie R, et al. Runners with patellofemoral pain have altered biomechanics which targeted interventions can modify: a systematic review and metaanalysis. Gait Posture 2016:45:69-82.

3 Maclachlan LR, Collins NJ, Matthews MLG, et al. The psychological features of patellofemoral pain: a systematic review. Br J Sports Med 2017;51:732-42.

14 Matthews M, Rathleff MS, Claus A, et al. Can we predict the outcome for people with patellofemoral pain? A systematic review on prognostic factors and treatment effect modifiers. Br J Sports Med 2017;51:1650-60.

5 Winters M, Holden S, Lura CB, Byrne C, et al. Comparative effectiveness of treatments for patellofemoral pain: a living systematic review with network meta-analysis. $\mathrm{Br} J$ Sports Med 2020. doi:10.1136/bjsports-2020-102819. [Epub ahead of print: 26 Oct 2020].

16 Macri EM, Hart HF, Thwaites D, et al. Medical interventions for patellofemoral pain and patellofemoral osteoarthritis: a systematic review. J Clin Med. In Press 2020;9. doi:10.3390/jcm9113397. [Epub ahead of print: 23 Oct 2020].

Holden S, Rathleff MS, Jensen MB, et al. How can we implement exercise therapy for patellofemoral pain if we don't know what was prescribed? A systematic review. $\mathrm{Br} J$ Sports Med 2018;52:385

18 Lack S, Barton C, Sohan O, et al. Proximal muscle rehabilitation is effective for patellofemoral pain: a systematic review with meta-analysis. Br J Sports Med 2015:49:1365-76

19 van der Heijden RA, Lankhorst NE, van Linschoten R, et al. Exercise for treating patellofemoral pain syndrome. Cochrane Database Syst Rev 2015;1:CD010387.

20 de Oliveira Silva D, Pazzinatto MF, Rathleff MS, et al. Patient education for Patellofemoral pain: a systematic review. J Orthop Sports Phys Ther 2020:50:388-96.

21 EQUATOR network. Available: https://www.equator-network.org/

22 Network E. Reporting checklists for medical researchers. Available: https://www. goodreports.org/

23 Delahunt $\mathrm{E}$, Thorborg K, Khan KM, et al. Minimum reporting standards for clinical research on groin pain in athletes. Br J Sports Med 2015;49:775-81.

24 Froud R, Eldridge S, Kovacs F, et al. Reporting outcomes of back pain trials: a modified Delphi study. Eur J Pain 2011;15:1068-74.

5 McAlindon TE, Driban JB, Henrotin Y, et al. OARSI clinical trials recommendations: design, conduct, and reporting of clinical trials for knee osteoarthritis. Osteoarthritis Cartilage 2015;23:747-60.

26 Moher D, Schulz KF, Simera I, et al. Guidance for developers of health research reporting guidelines. PLoS Med 2010;7:e1000217

27 Diamond IR, Grant RC, Feldman BM, et al. Defining consensus: a systematic review recommends methodologic criteria for reporting of Delphi studies. J Clin Epidemiol 2014:67:401-9

28 Gribble PA, Delahunt E, Bleakley C, et al. Selection criteria for patients with chronic ankle instability in controlled research: a position statement of the International ankle Consortium. Br J Sports Med 2014:48:1014-8.

29 Gribble PA, Delahunt E, Bleakley C, et al. Selection criteria for patients with chronic ankle instability in controlled research: a position statement of the International ankle Consortium. J Orthop Sports Phys Ther 2013;43:585-91.

30 Gribble PA, Delahunt E, Bleakley CM, et al. Selection criteria for patients with chronic ankle instability in controlled research: a position statement of the International ankle Consortium. J Athl Train 2014:49:121-7.

31 Clayton MJ. Delphi: a technique to harness expert opinion for critical decision-making tasks in education. Educ Psychol 1997:17:373-86

32 de Villiers MR, de Villiers PJT, Kent AP. The Delphi technique in health sciences education research. Med Teach 2005;27:639-43.

33 Fink A, Kosecoff J, Chassin M, et al. Consensus methods: characteristics and guidelines for use. Am J Public Health 1984;74:979-83.

34 Murry JW, Hammons JO. Delphi: a versatile methodology for conducting qualitative research. Rev High Ed 1995; 18:423-36.

35 Neal BS, Barton CJ, Birn-Jeffery A, et al. Increased hip adduction during running is associated with patellofemoral pain and differs between males and females: a casecontrol study. J Biomech 2019;91:133-9.

36 Willy RW, Manal KT, Witvrouw EE, et al. Are mechanics different between male and female runners with patellofemoral pain? Med Sci Sports Exerc 2012:44:2165-71.

37 Nakagawa TH, Moriya ETU, Maciel CD, et al. Trunk, pelvis, hip, and knee kinematics, hip strength, and gluteal muscle activation during a single-leg squat in males and females with and without patellofemoral pain syndrome. J Orthop Sports Phys Ther 2012;42:491-501
38 Bolgla LA, Earl-Boehm J, Emery C, et al. Comparison of hip and knee strength in males with and without patellofemoral pain. Phys Ther Sport 2015;16:215-21.

39 Rathleff MS, Rathleff CR, Crossley KM, et al. Is hip strength a risk factor for patellofemoral pain? A systematic review and meta-analysis. Br J Sports Med 2014;48:1088

40 Rathleff CR, Baird WN, Olesen JL, et al. Hip and knee strength is not affected in 12-16 year old adolescents with patellofemoral pain--a cross-sectional population-based study. PLoS One 2013;8:e79153.

41 Crossley KM. Is patellofemoral osteoarthritis a common sequela of patellofemoral pain? Br J Sports Med 2014:48:409-10.

42 Collins NJ, Oei EHG, de Kanter JL, et al. Prevalence of radiographic and magnetic resonance imaging features of Patellofemoral osteoarthritis in young and middle-aged adults with persistent Patellofemoral pain. Arthritis Care Res 2019;71:1068-73.

43 Powers CM, Witvrouw E, Davis IS, et al. Evidence-based framework for a pathomechanical model of patellofemoral pain: 2017 patellofemoral pain consensus statement from the 4th International Patellofemoral pain research retreat, Manchester, UK: Part 3. Br J Sports Med 2017;51:1713-23.

44 Kujala UM, Jaakkola LH, Koskinen SK, et al. Scoring of patellofemoral disorders. Arthroscopy 1993;9:159-63.

45 Crossley KM, Macri EM, Cowan SM, et al. The patellofemoral pain and osteoarthritis subscale of the KOOS (KOOS-PF): development and validation using the COSMIN checklist. Br J Sports Med 2018:52:1130-6.

46 Crossley KM, Bennell KL, Cowan SM, et al. Analysis of outcome measures for persons with patellofemoral pain: which are reliable and valid? Arch Phys Med Rehabil 2004;85:815-22

47 loannidis JPA, Greenland S, Hlatky MA, et al. Increasing value and reducing waste in research design, conduct, and analysis. Lancet 2014;383:166-75.

48 Vandenbroucke JP, von Elm E, Altman DG, et al. Strengthening the reporting of observational studies in epidemiology (STROBE): explanation and elaboration. PLOS Med 2007:4:e297.

49 Glaviano NR, Baellow A, Saliba S. Physical activity levels in individuals with and without patellofemoral pain. Phys Ther Sport 2017;27:12-16.

50 Benatti FB, Pedersen BK. Exercise as an anti-inflammatory therapy for rheumatic diseases-myokine regulation. Nat Rev Rheumatol 2015;11:86-97.

51 Booth FW, Laye MJ, Lees SJ, et al. Reduced physical activity and risk of chronic disease: the biology behind the consequences. Eur J App/ Physiol 2008;102:381-90

52 Orhan C, Van Looveren E, Cagnie B, et al. Are pain beliefs, Cognitions, and behaviors influenced by race, ethnicity, and culture in patients with chronic musculoskeletal pain: a systematic review. Pain Physician 2018:21:541-58.

53 Smith BE, Moffatt F, Hendrick P, et al. The experience of living with patellofemoral pain-loss, confusion and fear-avoidance: a UK qualitative study. BMJ Open 2018:8:e018624

54 Schiphof D, van Middelkoop M, de Klerk BM, et al. Crepitus is a first indication of patellofemoral osteoarthritis (and not of tibiofemoral osteoarthritis). Osteoarthritis Cartilage 2014;22:631-8.

55 Lo GH, Strayhorn MT, Driban JB, et al. Subjective Crepitus as a risk factor for incident symptomatic knee osteoarthritis: data from the osteoarthritis initiative. Arthritis Care Res 2018;70:53-60.

56 Artus M, Campbell P, Mallen CD, et al. Generic prognostic factors for musculoskeletal pain in primary care: a systematic review. BMJ Open 2017;7:e012901.

57 Kamper SJ, Maher CG, Mackay G. Global rating of change scales: a review of strengths and weaknesses and considerations for design. J Man Manip Ther 2009:17:163-70.

58 Martinez-Calderon J, Zamora-Campos C, Navarro-Ledesma S, et al. The role of selfefficacy on the prognosis of chronic musculoskeletal pain: a systematic review. J Pain 2018:19:10-34.

59 de Oliveira Silva D, Barton CJ, Briani RV, et al. Kinesiophobia, but not strength is associated with altered movement in women with patellofemoral pain. Gait Posture 2019;68:1-5.

60 De Oliveira Silva D, Willy RW, Barton CJ, et al. Pain and disability in women with patellofemoral pain relate to kinesiophobia, but not to patellofemoral joint loading variables. Scand J Med Sci Sports 2020;30:2215-21.

61 Maclachlan LR, Matthews M, Hodges PW, et al. The psychological features of patellofemoral pain: a cross-sectional study. Scand J Pain 2018;18:261-71.

62 Barton CJ, Merolli MA. It is time to replace publish or perish with get visible or vanish: opportunities where digital and social media can reshape knowledge translation. $\mathrm{Br} J$ Sports Med 2019;53:594-8.

63 Portney L, Watkins M. Foundations of clinical research: applications to practice. 2 edn. Upper Saddle River, NJ: Prentice-Hall, 2000

64 Moher D, Hopewell S, Schulz KF, et al. Consort 2010 explanation and elaboration: updated guidelines for reporting parallel group randomised trials. J Clin Epidemio 2010;63:e1-37.

65 Lowe A, Littlewood C, McLean S, et al. Physiotherapy and physical activity: a crosssectional survey exploring physical activity promotion, knowledge of physical activity guidelines and the physical activity habits of UK physiotherapists. BMJ Open Sport Exerc Med 2017;3:e000290 
66 Hoffmann TC, Glasziou PP, Boutron I, e al, et al. Better reporting of interventions: template for intervention description and replication (TIDieR) checklist and guide. BMJ 2014;348:g1687.

67 Slade SC, Dionne CE, Underwood M, et al. Consensus on exercise reporting template (CERT): explanation and elaboration statement. Br J Sports Med 2016;50:1428-37.

68 Slade SC, Dionne CE, Underwood M, et al. Consensus on exercise reporting template (CERT): modified Delphi study. Phys Ther 2016;96:1514-24.

69 Toigo M, Boutellier U. New fundamental resistance exercise determinants of molecular and cellular muscle adaptations. Eur J Appl Physiol 2006;97:643-63.

70 Carpenter $\mathrm{CR}$, Cone DC, Sarli CC. Using publication metrics to highlight academic productivity and research impact. Acad Emerg Med 2014;21:1160-72.

71 Wallis JA, Roddy L, Bottrell J, et al. A systematic review of clinical practice guidelines for physical therapist management of Patellofemoral pain. Phys Ther 2021;101. doi:10.1093/ptj/pzab021. [Epub ahead of print: 03 Mar 2021].
72 Smith BE, Hendrick P, Bateman M, et al. Current management strategies for patellofemoral pain: an online survey of 99 practising UK physiotherapists. BMC Musculoskelet Disord 2017;18:181.

73 Barton CJ, Ezzat AM, Bell EC, et al. Knowledge, confidence and learning needs of physiotherapists treating persistent knee pain in Australia and Canada: a mixedmethods study. Physiother Theory Pract. In Press 2021:1-13.

74 Rice DB, Raffoul H, loannidis JPA, et al. Academic criteria for promotion and tenure in biomedical sciences faculties: cross sectional analysis of international sample of universities. BMJ 2020;369:m2081.

75 Vicenzino B, Rathleff MS, Holden S. Clinical and research priorities on pain and psychological features in individuals who have patellofemoral pain: an international Delphi consensus study of patients and health care professionals. Under review 2021. 